\title{
Renal Replacement Therapy in Critically Ill: Current Trend and New Direction
}

\author{
Sarwar Iqbal ${ }^{1}$, Mohammad Omar Faruq ${ }^{2}$
}

Abstract

Critically ill patients often present with renal dysfunction. Acute kidney injury (AKI) is common in intensive care unit (ICU) patients and is often a component of multiple organ dysfunction syndrome (MODS). Renal replacement therapy (RRT) plays a significant role in management of acute and chronic renal failure in ICU.

During the last decade RRT has made remarkable progress in management of renal dysfunction of critically ill. The Acute Dialysis Quality Initiative conceived in 2002 proposed RIFLE classification for AKI (risk, injury, failure, loss, end-stage kidney disease) using serum creatinine and urine output in critically ill patients. More recently, the Acute Kidney Injury Network (AKIN) has been introduced for staging AKI.

Studies have shown that mortality increases proportionately with increasing severity of AKI. In patients with severe AKI requiring RRT mortality is approximately $50 \%$ to $70 \%$ according to one study and even a small changes in serum creatinine are associated with increased mortality.

The most common causes of AKI in ICU are sepsis, hypovolemia, low cardiac output and drugs. The various techniques of RRT used in ICU include intermittent hemodialysis (IHD), continuous RRT (CRRT), sustained low efficiency dialysis (SLED) and peritoneal dialysis (PD). It is preferable to use RRT at either RIFLE injury type or at AKIN stage II in critically ill patients.

IHD is commonly used in hemodynamically stable ICU patients. Because of high dialysate $(500 \mathrm{ml} / \mathrm{min})$ IHD may cause hypotension in some patients. Solute removal may be episodic and often result in inferior uraemic control and acid base control.

CRRT is usually initiated with a blood flow of 100 to $200 \mathrm{ml} / \mathrm{min}$. and thus hemodynamic instability associated with IHD is avoided. Major advantages of CRRT include continuous control of fluid status, hemodynamic stability and control of acid base status. It is expensive and there is high risk of bleeding because of use of high dose of IV heparin.

SLED has been found to be safe and effective in critically ill patients with hemodynamic instability. It uses the same dialysis machine of IHD and combines the effectiveness of CRRT in unstable patients and easy operability of IHD. It is also cost effective.

$P D$ is initiated in ICU for AKI patients when bedside IHD is not available. It is good for hemodynamically unstable patients when IHD or CRRT is difficult. In patients on mechanical ventilator, PD interferes with function of diaphragm causing decrease in lung compliance.

Early identification of AKI with bio markers is an important step in improving outcomes of AKI. These bio markers help early detection of AKI before the onset of rise in serum creatinine. Serum cystatin $C$ is one of the sensitive bio markers of small changes in Glomerular filtration rate (GFR) and has been found to be useful.

AKI in the ICU most commonly results from multiple insults. Therefore appropriate and early identification of patients at risk of AKI provides an opportunity to prevent subsequent renal insults. This strategy will influence overall ICU morbidity and mortality.

Key words: $A K I$ in ICU, RRT, SLED, PD, CRRT

\section{Introduction}

Acute kidney injury is common in critically ill patients and is

1. Dr. Sarwar Iqbal, MD (Nephrology), Associate Professor, Department of Nephrology, BIRDEM General Hospital, Shahbag, Dhaka 1000, Bangladesh.

2. Prof. Mohammad Omar Faruq, MD, FACP, FACEP, FCCM, FCPS, Professor, Department of Critical Care Medicine, BIRDEM General Hospital, Shahbag, Dhaka 1000, Bangladesh.

Corresponding Author:

Dr Sarwar Iqbal

Associate Professor \& Head of the Department of Nephrology BIRDEM General Hospital

122, Kazi Nazrul Islam Avenue, Dhaka 1000, Bangladesh

E mail: sarwariqbal2003@yahoo.com associated with significant morbidity and mortality. Diagnosing and managing critically ill patients with renal dysfunction is an important part in the management of critically ill. Renal replacement therapy (RRT) is being widely used in intensive care. Acute kidney injury (AKI) is frequently present in critically ill patients of the intensive care unit (ICU) as a part of multiple organ dysfunction syndrome (MODS). These patients have various co-morbid conditions and are on various life-supportive modalities. Fluid overload and electrolyte and acid-base disturbances and drugs may further injure their organ systems. RRT plays a significant role in ICU in the treatment of patients with renal failure, acute as well as chronic. However, the term 'RRT' is not 
accurate as it is not possible for dialysis to replace all functions of the kidney. 'Renal support therapy' would be a better terminology to refer to this modality of treatment ${ }^{1}$. The field of RRT has undergone remarkable changes over the last decade and has been evolving rapidly.

Acute kidney injury (AKI), previously termed acute renal failure, refers to a sudden decline in kidney function causing disturbances in fluid, electrolyte, and acid-base balance because of a loss in small solute clearance and decreased glomerular filtration rate (GFR). The nomenclature shift to AKI describes more perfectly the spectrum of disease from subclinical injury to complete organ failure.

\section{Defining AKI in ICU}

More than 35 definitions of AKI currently exist in the literature $^{2}$. The Acute Dialysis Quality Initiative convened in 2002 and proposed the RIFLE classification (risk, injury, failure, loss, end-stage kidney disease) specifically for AKI using serum creatinine and urine output in critically ill patients. More recently the Acute Kidney Injury Network (AKIN) has been introduced for staging AKI.

The RIFLE classification ${ }^{3}$ was proposed by the Acute Dialysis Quality Initiative specifically for AKI in critically ill patients. The Acute Kidney Injury Network (AKIN) criteria ${ }^{4}$ further modified the RIFLE criteria (Table I). The most current consensus diagnostic criteria for AKI is "an abrupt (within 48 hours) reduction in kidney function, currently defined as an absolute increase in serum creatinine of $\geq 0.3$ $\mathrm{mg} / \mathrm{dL}(\geq 26.4 \mu \mathrm{mol} / \mathrm{L})$, a percentage increase in serum creatinine of $\geq 50 \%$ (1.5-fold from baseline), or a reduction in urine output (documented oliguria of $<0.5 \mathrm{ml} / \mathrm{kg} / \mathrm{hr}$ for $>6$ hours)."

Table I $* 3,4$

\section{Epidemiology of AKI in ICU}

$\mathrm{AKI}$ in the ICU is common, increasing in incidence ${ }^{5,6}$ and is associated with a substantial increase in morbidity and mortality 7,8 . AKI occurs in approximately $7 \%$ of all hospitalized patients ${ }^{9}$ and in up to $36 \%$ to $67 \%$ of critically ill patients depending on the definition used ${ }^{10}$. Based on 75,000 critically ill adults, more severe AKI occurs in $4 \%$ to $25 \%$ of all ICU admissions ${ }^{8,10}$. On average, $5 \%$ to $6 \%$ of ICU patients with AKI require renal replacement therapy (RRT). Reported mortality in ICU patients with AKI varies considerably between studies depending on AKI definition and the patient population studied (e.g., sepsis, trauma, cardiothoracic surgery, or contrast nephropathy). In the majority of studies, mortality increases proportionately with increasing severity of $\mathrm{AKI}^{11}$. In patients with severe $\mathrm{AKI}$ requiring RRT, mortality is approximately $50 \%$ to $70 \%{ }^{12}$. While AKI requiring RRT in the ICU is a well-recognized independent risk factor for in-hospital mortality ${ }^{13}$, even small changes in serum creatinine (S. Cr) are associated with increased mortality. Notably, multiple studies of patients with AKI and sepsis, mechanical ventilation, major trauma, cardiopulmonary bypass, and burn injuries have consistently demonstrated an increased risk of death despite adjustment for co morbidities and severity of illness. Morbidity, a less appreciated consequence of AKI in the ICU, is associated with increased cost, increased length of stay, and increased risk of chronic kidney disease (CKD), including end-stage kidney disease ${ }^{14}$. The true incidence of CKD after AKI is unknown because epidemiologic studies do not routinely or consistently report rates of renal recovery and those that do use variable definitions.

\section{Common causes of AKI in ICU}

The most common causes of AKI in the ICU are sepsis, hypovolemia causing renal hypoperfusion, low cardiac output and drugs. Other common causes include hepatorenal syndrome, rhabdomyolysis, urinary flow obstruction, trauma,

\begin{tabular}{|c|c|c|c|c|c|}
\hline RIFLE & S. Cr criteria & UOP criteria & AKIN stage & S. Cr criteria & UOP criteria \\
\hline $\mathrm{R}$ & $\begin{array}{l}\text { Increase in } \mathrm{S} . \mathrm{Cr} . \geq 1.5 \text { baseline } \\
\text { or decrease in } \mathrm{GFR} \geq 25 \%\end{array}$ & $\begin{array}{l}<0.5 \mathrm{ml} / \mathrm{kg} / \mathrm{hr} \\
\geq 6 \mathrm{hrs}\end{array}$ & 1 & $\begin{array}{l}\text { Increase in } \mathrm{S} . \mathrm{Cr} . \geq 26.2 \mathrm{mmol} / \mathrm{L} \\
\text { or increase to } \geq 150-199 \% \\
\text { (1.5 to } 1.9 \text { fold) from baseline }\end{array}$ & $\begin{array}{l}<0.5 \mathrm{ml} / \mathrm{kg} / \\
\mathrm{hr} \geq 6 \mathrm{hrs}\end{array}$ \\
\hline I & $\begin{array}{l}\text { Increase in S.Cr. } \geq 2.0 \text { baseline } \\
\text { or decrease in GFR } \geq 50 \%\end{array}$ & $\begin{array}{l}<0.5 \mathrm{ml} / \mathrm{kg} / \mathrm{hr} \\
\geq 12 \mathrm{hrs}\end{array}$ & 2 & $\begin{array}{l}\text { Increase in S.Cr. } \geq 200-299 \% \\
(>2-2.9 \text { fold) from baseline }\end{array}$ & $\begin{array}{l}<0.5 \mathrm{ml} / \mathrm{kg} / \\
\mathrm{hr} \geq 12 \mathrm{hrs}\end{array}$ \\
\hline $\mathrm{F}$ & $\begin{array}{l}\text { Increase in } \mathrm{S} . \mathrm{Cr} . \geq 3.0 \text { baseline } \\
\text { or decrease in } \mathrm{GFR} \geq 75 \% \text { or } \\
\text { absolute } \mathrm{S} . \mathrm{Cr} \geq 354 \mathrm{mmol} / \mathrm{L} \text { with an } \\
\text { acute rise of at least } 44 \mathrm{mmol} / \mathrm{L}\end{array}$ & $\begin{array}{l}<0.3 \mathrm{ml} / \mathrm{kg} / \mathrm{hr} \geq 24 \mathrm{hrs} \\
\quad \text { or anuria } \geq 12 \mathrm{hrs}\end{array}$ & 3 & $\begin{array}{l}\text { Increase in } \mathrm{S} . \mathrm{Cr} . \geq 300 \% \\
\text { ( } \geq 3 \text { fold) from baseline or } \\
\mathrm{S} \text {. Cr. } \geq 354 \mathrm{mmol} / \mathrm{L} \text { with an } \\
\text { acute rise of at least } 44 \mathrm{mmol} / \mathrm{L} \\
\text { or initiation of RRT }\end{array}$ & $\begin{array}{l}<0.3 \mathrm{ml} / \mathrm{kg} / \mathrm{hr} \geq 24 \mathrm{hrs} \\
\quad \text { or anuria } \geq 12 \mathrm{hrs}\end{array}$ \\
\hline $\mathrm{L}$ & $\begin{array}{l}\text { Persistent loss of kidney } \\
\text { function for }>4 \text { weeks }\end{array}$ & & & & \\
\hline $\mathrm{E}$ & $\begin{array}{l}\text { Persistent loss of kidney } \\
\text { function for }>3 \text { months }\end{array}$ & & & & \\
\hline
\end{tabular}

*AKIN $=$ Acute kidney injury network, GFR = Glomerular filtration rate, RIFLE $=$ Risk, injury, failure, loss, end-stage kidney disease, $\mathrm{S} . \mathrm{Cr}=$ Serum creatinine, $\mathrm{UOP}=$ Urine output 
surgery etc. Angiotensin Converting Enzyme (ACE) Inhibitor and Angiotensin II Receptor Blocker (ARB) are other potential aggravating factors in the development of AKI and thus, renal function should be checked at three to five days interval when an ACE inhibitor or ARB is prescribed in a patient who is at risk for AKI.

\section{Indications of RRT}

Severe AKI results in deregulation in the homeostasis of fluid, potassium, metabolic acids, and waste products. RRT aids to prevent life-threatening complications and to improve homeostasis.

Prevailing criteria ${ }^{15}$ for the initiation of RRT in ICU include

- Oliguria (urine output $<200 \mathrm{ml} / 12 \mathrm{~h}$ )

- Anuria (urine output: 0-50 ml/12 h)

- $\quad$ Blood urea $>35 \mathrm{mmol} / \mathrm{L}(>98 \mathrm{mg} / \mathrm{dL})$

- Serum creatinine $>400 \mathrm{mmol} / \mathrm{L}(>4.5 \mathrm{mg} / \mathrm{dL})$

- Uncompensated metabolic acidosis $(\mathrm{pH}<7.1)$

- Serum $\mathrm{K}^{+}>6.5 \mathrm{mmol} / \mathrm{L}$ or rapidly rising values

- $\quad$ Serum $\mathrm{Na}^{+}>160 \mathrm{mmol} / \mathrm{L}$

- Pulmonary edema refractory to diuretics

- Uremic complications (encephalopathy /pericarditis)

- Overdose with a dialyzable toxin

- Hyperthermia and hypothermia

Additional indications for RRT are

- Cardiac failure

- Patients requiring a large amount of fluid, parenteral nutrition or blood products, but at risk of developing pulmonary edema or ARDS

- Hyperthermia (core temperature $>39.5^{\circ} \mathrm{C}$ ) or hypothermia (core temperature $<37^{\circ} \mathrm{C}$ )

AKI in the ICU often occurs as a part of MODS, and such patients may have less tolerance of metabolic derangements, such as acidosis and electrolyte imbalances. RRT should be initiated in these patients before the development of extreme metabolic derangements. In patients who require renal support because of metabolic derangements, RRT should not be delayed.

It is preferable to commence RRT at either RIFLE injury stage or at AKIN stage II in critically ill patients when both criteria (urine output and serum creatinine) are included.

Modes of RRT: The common modes include,

- Intermittent Hemodialysis (IHD)

- Continuous RRT (CRRT)

- $\quad$ Sustained Low Efficiency Dialysis (SLED)

- Peritoneal Dialysis (PD) which can be done by either of the following.

a) Acute Peritoneal Dialysis (APD) by a rigid catheter.

b) Continuous Ambulatory Peritoneal Dialysis (CAPD) conventional or cycler assisted by a flexible (Tenckhoff) catheter.

\section{Intermittent Hemodialysis (IHD)}

This technique uses high dialysate flows $(500 \mathrm{ml} / \mathrm{min})$. Treatment is applied for short periods of time ( $3-4$ hours), usually every other day.

IHD has several disadvantages. A reasonably large volume of fluid has to be removed over a short period of time, which can result in hypotension. Repeated hypotensive episodes may delay renal recovery. The use of CRRT is preferred for its improved cardiovascular tolerance over daily intermittent hemodialysis. Solute removal in IHD is episodic. This results in inferior uremic control and acid-base control. Limited fluid and uremic control imposes unnecessary limitations on nutritional support. Rapid solute shifts may increase brain water content and increase in intracranial pressure. Standard low-flux dialyzing membranes trigger the activation of several inflammatory pathways when compared to high-flux synthetic membranes (also used for continuous haemofiltration). This pro-inflammatory effect contributes to further renal damage and delays recovery or even affects mortality.

\section{Continuous RRT (CRRT)}

The hemodynamic instability that is often associated with IHD, along with the risk of injury to the recovering kidney, led to the invention of Continuous renal replacement therapy (CRRT) techniques. CRRT is usually initiated with a blood flow of $100 \mathrm{~mL} / \mathrm{min}$ and gradually increased up to 200 $\mathrm{mL} / \mathrm{min}$. CRRT is inherently complex with the requirement for anti-coagulation and the use of high volumes of fluid and is much costlier compared to IHD.

The advantages of CRRT include continuous control of fluid status, hemodynamic stability, control of acid-base status, ability to provide protein-rich nutrition while achieving uremic control, control of electrolyte balance including phosphate and calcium balance, prevention of swings in intracerebral water, minimal risk of infection, and high level of biocompatibility. CRRT has to be considered for patients with cerebral edema, severe hemodynamic instability, persistent on-going metabolic acidosis, and large fluid removal requirements.

Disadvantages of CRRT include higher risk of bleeding due to higher dosage of heparin required, restricted patient mobility. It requires trained personnel and it is expensive.

\section{Sustained Low Efficiency Dialysis (SLED)}

Hybrid therapies like SLED and extended daily dialysis have been shown to be safe and effective in critically ill patients ${ }^{16}$. Slow low efficiency diafiltration (SLED-f) by combining SLED with ultrafiltration has been shown to provide stable renal replacement therapy ${ }^{17}$.

SLED has better hemodynamic tolerability. It involves no extra machine or device. It combines the effectiveness of CRRT in hemodynamically unstable patients and easy operability of IHD. It involves less heparin dosages and is cost effective. SLED is better for hemodynamically unstable cardiac patients. 


\section{Peritoneal Dialysis (PD)}

Peritoneal dialysis (PD) was the first modality of renal replacement therapy used for AKI patients ${ }^{18}$. In the 1970s, acute PD was widely accepted for AKI treatment, but its practice declined in favor of hemodialysis ${ }^{19}$. It is frequently used in developing countries because of its lower cost and minimal infrastructural requirements. Recently, interest in using PD to manage AKI patients has been increasing. One important question is whether $\mathrm{PD}$ can provide adequate metabolic and fluid control for treating AKI patients.

The work by Gabriel et $\mathrm{a}^{20}$ showed that, with careful thought and planning, PD could successfully treat critically ill patients. To overcome some of the classic limitations of PD use in AKI, such as a high chance of infection and no metabolic control, they proposed the use of cycles, flexible catheter, and a high volume of dialysis fluid.

In peritoneal dialysis, $1.5-3 \mathrm{~L}$ of peritoneal dialysate solution is infused into the peritoneal cavity and allowed to dwell for a set period of time, usually 2 to 4 hours. A combination of convective clearance and diffusive clearance occurs. The clearance of solutes and water depends on the balance between the movement of solutes and water into the peritoneal cavity versus absorption from the peritoneal cavity into the peritoneal capillary circulation across the peritoneal membrane. The rate of diffusion diminishes with time and eventually stops when equilibration between plasma and dialysate is reached. PD in ICU is indicated when the patient is so hemodynamically unstable that transport to the dialysis unit situated away from the ICU is forbidden. This is especially true when bedside haemodialysis is not available in ICU. PD is found to be more effective in AKI in extremes of age i.e. pediatric patients and elderly patients.

PD is good for hemodynamically unstable patients where IHD or CRRT is difficult. There are no hazards of heparin. Insulin may also be added in patients with diabetes mellitus. A non-absorbable carbohydrate osmotic agent, icodextrin, has been found to be associated with more efficient ultrafiltration than dextrose-containing solutions ${ }^{21}$. PD is also a cheap modality of treatment for AKI in resource poor countries.

Disadvantages of PD include peritonitis, weight gain, hyperglycemia, fluid leaks, protein loss and interference with diaphragm function reducing lung compliance especially when patient is receiving positive pressure breathing by mechanical ventilator.

\section{Current trend in RRT}

Results from a large prospective multi-centered observational study of 1200 patients were inconsistent and dependent on the definition of "early" or "late" initiation of RRT ${ }^{22}$. In this study, "late" initiation of RRT was associated with worse out comes (higher crude mortality, longer duration of RRT, increased hospital length of stay, and greater dialysis dependence) when "late" was defined relative to date of ICU admission. A recent meta-analysis nine randomized trials (RCT) comparing intermittent to continuous renal replacement therapy (intermittent RRT vs. CRRT) in AKI demonstrated no difference in mortality or renal recovery defined as independence from $\mathrm{RRT}^{23}$. Two studies have shown that CRRT is associated with better long-term kidney recovery when compared to intermittent $\mathrm{RRT}^{24,25}$. In contrast, four RCT that included renal recovery as a primary outcome showed no difference in need for chronic $\mathrm{RRT}^{26-28}$. In the absence of definitive data in support of a particular modality, the choice of RRT modality is currently influenced by multiple factors, including individual site availability, expertise, resources, cost, and likely clinician bias. Hybrid therapies include SLED and extended daily dialysis. These modalities utilize standard intermittent hemodialysis machines but provide a slower solute and fluid removal similar to CRRT technologies. Although there have been no prospective randomized trials evaluating outcomes, hybrid therapies have been shown to be safe and effective alternatives to treating AKI in critically ill patients $^{29,30}$. The question of optimal modality has not yet been definitively answered. According to several studies in critically ill patients, serum cystatin $\mathrm{C}$ is better than S.Cr for early detection of $\mathrm{AKI}^{31,32}$ and as a more sensitive marker of small changes in GFR. However in one smaller study there was no correlation between cystatin $\mathrm{C}$ and $\mathrm{S} . \mathrm{Cr}^{33}$. In a recent study, urinary cystatin $\mathrm{C}$ but not plasma cystatin $\mathrm{C}$ was superior to conventional plasma markers in the early identification of AKI after cardiac surgery ${ }^{34}$.

\section{Future trends}

Early identification of AKI with novel candidate biomarkers is an important step in improving outcomes in AKI. These biomarkers help not only in early detection of AKI before the onset of a rise in the serum creatinine, but also aid in the differential diagnosis and prognosis. Serum cystatin $\mathrm{C}$ is a sensitive marker of small changes in GFR and has been found to be a useful biomarker for early detection of $\mathrm{AKI}^{35,36}$. In a recent study, urinary cystatin $\mathrm{C}$ was found to be superior to conventional plasma markers in the early identification of AKI in post-cardiac surgery patients ${ }^{37}$. Most promising early biomarkers of AKI are neutrophil gelatinase-associated lipocalin (NGAL), kidney injury molecule-1 (KIM-1), and interleukin (IL) $-18^{38}$.

\section{Prevention of AKI in critically ill: A novel approach}

Those patients prone to develop AKI as evidenced by early biomarkers and with hypotension can use Intra-aortic balloon counter pulsation set just below the renal arteries to ensure perfusion of both the kidneys. This approach is hypothetical and requires study on experimental animals and then on human subjects.

\section{Conclusion}

The field of RRT has made remarkable progress over the last decade and is continuing to evolve rapidly. CRRT is now firmly established throughout the world and is perhaps the most commonly used form of RRT. CRRT seems to be superior to IHD with regard to physiological end points. Modifications of IHD, such as SLED, are able to combine the advantages of both IHD and CRRT. PD particularly CAPD is emerging mode of RRT in critically ill. AKI in the ICU most commonly results from multiple insults. Therefore, appropriate and early identification of patients at risk for AKI provides an 
opportunity to prevent subsequent renal insults and ultimately influence overall ICU morbidity and mortality. Strategies to prevent AKI in these patients are of crucial importance. Critical care nephrology is a fast-emerging subspeciality, and critical care physicians are likely to play a paramount role in the management of patients with renal failure.

\section{References}

1. Brochard L, Abroug F, Brenner M, Broccard AF, Danner RL, Ferrer $\mathrm{M}$ et al. ATS/ERS/ESICM/SCCM/SRLF ad hoc committee on acute renal failure. An official ATS/ERS/ESICM/SCCM/SRLF statement: Prevention and management of acute renal failure in the ICU patient: An international consensus conference in intensive care medicine. Am J Respir Crit Care Med 2010; 181: 1128-55.

2. Mehta RL, Chertow GM. Acute renal failure definitions and classification: Time for change? J Am Soc Nephrol 2003; 14: 2178-87.

3. Bellomo R, Ronco C, Kellum JA, Mehta RL, Palevsky P. Acute renal failure - definition, outcome measures, animal models, fluid therapy and information technology needs: The second international consensus conference of the acute dialysis quality initiative (ADQI) Group. Crit Care 2004; 8: R204-12.

4. Mehta RL, Kellum JA, Shah SV, Molitoris BA, Ronco C, Warnock DG, et al. Acute Kidney Injury Network: Report of an initiative to improve outcomes in acute kidney injury. Crit Care 2007; 11: R31.

5. Bagshaw SM, George C, Bellomo R. Changes in the incidence and outcome for early acute kidney injury in a cohort of Australian intensive care units. Crit Care 2007; 11: R68.

6. Xue JL, Daniels F, Star RA, Kimmel PL, Eggers PW, Molitoris BA et al. Incidence and mortality of acute renal failure in Medi-care beneficiaries, 1992 to 2001. J am Soc Nephrol 2006; 17(4): 1135-42.

7. Chertow GM, Soroko SH, Paganini EP, Cho KC, Himmelfarb J, Ikizler TA et al. Mortality after acute renal failure: Models for prognostic stratification and risk adjustment. Kidney international 2006; 70: 1120-6.

8. Hoste EA, Clermont G, Kersten A, et al. RIFLE criteria for acute kidney injury are associated with hospital mortality in critically ill patients: A cohort analysis. CritCare 2006; 10: R73.

9. Nash K, Hafeez A, Hou S. Hospital-acquired renal insufficiency. Am J Kidney Dis 2002; 39: 930-6.

10. Ostermann M, Chang RW. Acute kidney injury in the intensive care unit according to RIFLE. Crit Care Med 2007; 35: 1837-43; quiz 1852

11. Lopes JA, Jorge S, Resina C et al. Prognostic utility of RIFLE for acute renal failure in patients with sepsis. Crit Care 2007; 11: 408.

12. Bagshaw SM, Laupland KB, Doig CJ, et al. Prognosis for long-term survival and renal recovery in critically ill patients with severe acute renal failure: A population-based study. Crit Care 2005; 9: R700-R709.

13. Chertow GM, Levy EM, Hammermeister KE, et al. Independent association between acute renal failure and mortality following cardiac surgery. Am J Med 1998; 104: 343-8.

14. Korkeila M, Ruokonen E, Takala J. Costs of care, long-term prognosis and quality of life in patients requiring renal replacement therapy during intensive care. Intensive Care Med 2000; 26: 1824-31.

15. Bellomo R, D'Intini V, Ronco C. In Textbook of critical care. 5th ed. Philadelphia: Elsevier Saunders; 2005. Renal replacement therapy in ICU; p.1152.

16. Marshall MR, Golper TA, Shaver MJ, Alam MG, Chatoth DK. Sustained low efficiency dialysis for critically ill patients requiring renal replacement therapy. Kidney Int 2001; 60: 777-85.

17. Marshall MR, Ma T, Galler D, Rankin AP, Williams AB. Sustained low-efficiency daily diafiltration (SLEDD-f) for critically ill patients requiring renal replacement therapy: Towards an adequate therapy. Nephrol Dial Transplant 2004; 19: 877-84.
18. Steiner RW. Continuous equilibration peritoneal dialysis in acute renal failure. Perit Dial Int 1989; 9: 5-7.

19. Gabriel DP, Nascimento GVR, Caramori JT, Martim LC, Barretti P, Balbi AL. Peritoneal dialysis in acute renal failure. Ren Fail 2006; 28: 451-6.

20. Gabriel DP, Nascimento GVR, Caramori JT, Martim LC, Barretti P, Balbi AL. High volume peritoneal dialysis for acute renal failure. Perit Dial Int 2007; 27: 277-82.

21. Finkelstein F, Healy H, Abu-Alfa A, Ahmad S, Brown F, Gehr T, et al. Superiority of icodextrin compared with $4.25 \%$ dextrose for peritoneal ultrafiltration. J Am Soc Nephrol 2005; 16: 546-54.

22. Bagshaw SM, Uchino S, Bellomo R, et al. Timing of renal replacement therapy and clinical outcomes in critically ill patients with severe acute kidney injury. J Crit Care 2009; 24: 129-40.

23. Bagshaw SM, Berthiaume LR, Delaney A, et al. Continuous versus intermittent renal replacement therapy for critically ill patients with acute kidney injury: A meta-analysis. Critical care medicine 2008; 36: 610-7.

24. Uchino S, Bellomo R, Kellum JA, et al. Patient and kidney survival by dialysis modality in critically ill patients with acute kidney injury. Int J Artif Organs 2007; 30: 281-92.

25. Bell M, Granath F, Schon S, et al. Continuous renal replacement therapy is associated with less chronic renal failure than intermittent haemodialysis after acute renal failure. Intensive Care Med 2007; 33: 773-80.

26. Vinsonneau $\mathrm{C}, \mathrm{Camus} \mathrm{C}, \mathrm{Combes} \mathrm{A}$, et al. Continuous veno venous haemo diafiltration versus intermittent haemodialysis for acute renal failure in patients with multiple-organ dysfunction syndrome: A multicentre ran-domised trial. Lancet 2006; 368: 379-85.

27. Augustine JJ, Sandy D, Seifert TH, et al. A randomized controlled trial comparing intermittent with continuous dialysis in patients with ARF. Am J Kidney Dis 2004; 44: 1000-7.

28. Lins RL, Elseviers MM, Van der Niepen P, et al. Intermittent versus continuous renal re- placement therapy for acute kidney injury patients admitted to the intensive care unit: Results of a randomized clinical trial. Nephrol Dial Transplant 2009; 24: 512-8.

29. Kumar VA, Yeun JY, Depner TA, et al. Extended daily dialysis vs. continuous hemodialysis for ICU patients with acute renal failure: A two-year single center report. Int J Artif Organs 2004; 27: 371-9.

30. Kielstein JT, Kretschmer U, Ernst T, et al. Efficacy and cardiovascular tolerability of extended dialysis in critically ill patients: A randomized controlled study. Am J Kidney Dis 2004; 43: 342-9.

31. Ahlstrom A, Tallgren M, Peltonen S, et al. Evolution and predictive power of serum cystatin C in acute renal failure. Clin Nephrol 2004; 62: 344-50.

32. Herget-Rosenthal S, Marggraf G, Husing J, et al. Early detection of acute renal failure by serum cystatin C. Kidney International 2004; 66: 1115-22.

33. Mazul-Sunko B, Zarkovic N, Vrkic N, et al. Proatrial natriuretic peptide (1-98), but not cystatin $\mathrm{C}$, is predictive for occurrence of acute renal insufficiency in critically ill septic patients. Nephron Clin Pract 2004; 97: c103-c107.

34. Koyner JL, Bennett MR, Worcester EM, et al. Urinary cystatin C as an early biomarker of acute kidney injury following adult cardiothoracic surgery. Kidney Int 2008; 74: 1059-69.

35. Herget-Rosenthal S, Marggraf G, Husing J, Göring F, Pietruck F, Janssen $\mathrm{O}$, et al. Early detection of acute renal failure by serum cystatin C. Kidney Int. 2004; 66: 1115-22.

36. Delanaye P, Lambermont B, Chapelle JP, Gielen J, Gerard P, Rorive G. Plasmatic cystatin $\mathrm{C}$ for the estimation of glomerular filtration rate in intensive care units. Intensive Care Med 2004; 30: 980-3.

37. Koyner JL, Bennett MR, Worcester EM, Ma Q, Raman J, Jeevanandam $\mathrm{V}$, et al. Urinary cystatin $\mathrm{C}$ as an early biomarker of acute kidney injury following adult cardiothoracic surgery. Kidney Int 2008; 74: 1059-69.

38. Parikh CR, Mishra J, Thiessen-Philbrook H, Dursun B, Ma Q, Kelly C, et al. Urinary IL-18 is an early predictive biomarker of acute kidney injury after cardiac surgery. Kidney Int. 2006; 70: 199-203. 